\title{
A casa do tio e a casa do sogro: metodologias da antropologia do parentesco no País Basco
}

DoI

http://dx.doi.org/10.11606/ 2179-0892.ra.2017.137314

\section{Ion F. de las Heras}

- Universidade Federal de São Carlos / São Carlos, SP, Brasil

$\boldsymbol{\nabla}$ iongueras@hotmail.com

\section{RESUMO}

Neste artigo pretendo mostrar como a progressiva atenção que a antropologia feita no País Basco no decorrer do século XX deu ao conceito que vincula casa e família, etxea, não foi o produto direto de uma teoria positiva propriamente nativa, mas derivado de uma reação sobre o debate mainstream da teoria antropológica, que durante várias décadas se localizou no âmbito da terminologia do parentesco. Percorrerei alguns momentos relevantes neste caminho, e estabelecerei um paralelo com as estratégias teóricas que Freeman, Lévi-Strauss e Schneider desenvolveram para enfrentar problemas relativos à inadequação de conceitos teóricos em determinadas formas de organização social. Assim, desde uma perspectiva epistemológica que tome a prática antropológica sistemicamente, procurarei indicar as possibilidades de um diálogo entre metodologias. 
Uma sensibilidade atual confere significância a fatos históricos e etnológicos; com a mudança das perspectivas, muda também o passado (Herzfeld, [2005] 2008: 136).

\section{INTRODUÇÃO}

São poucas as questões relativas ao País Basco $^{2}$ que ocupam um lugar relevante nos debates antropológicos contemporâneos. A presença midiática internacional das ações do grupo independentista armado E.T.A. (Euskadi ta Askatasuna) contribuiu para a consolidação do nacionalismo e da violência política basca como os tópicos que concentram a maioria dos ol hares dirigidos à região. No entanto, no começo do século XX o País Basco foi um foco de intensidade que aglutinou o trabalho de numerosos arqueólogos, linguistas, historiadores, folcloristas e antropólogos europeus interessados numa pluralidade de assuntos de escalas diversas cujas fronteiras se estendiam muito além do contexto local. A profusão desses estudos e debates contribui de tal modo à demarcação de um âmbito social, linguístico, cultural e territorial singularizado que hoje autores como Zulaika afirmam que foram a "antropologia etnográfica e a linguística as que tentaram proporcionar ao basco a narrativa fundacional sobre a qual cimentar sua identidade" (2000:19).

O nacionalismo basco reconhece na língua, o euskera, um dos fatores culturais predominantes na composição de sua identidade. De fato, o euskera, ou basco, é uma língua singular: ela compõe a totalidade de um tronco linguístico isolado que se acredita anterior ao tronco indoeuropeu ${ }^{3}$, o que levou a uma idealização popular dos bascos como históricos resistentes antiglobalização e como portadores de uma raiz que os coloca num presente em contato direto com a pré-história (Zulaika, 2000: 23). No entanto, antes da consolidação desse mito moderno foi preciso que, no contexto da primeira metade do século XX, o euskera se constituísse mais ativamente como o loci de diversos debates intelectuais e acadêmicos, nos quais numerosos eruditos divulgaram disparatadas teorias sociais baseadas em duvidosos procedimentos de fabulação etimológica (Aranzadi, [1984] 2000). Neste ponto, o estudo do parentesco, mais concretamente da terminologia do parentesco, cumpriu uma função específica, uma vez que, ansiosos por penetrar "num passado inexplorado e em grande parte inexplorável", numerosos autores procuraram "na nomenclatura basca o reflexo das antigas relações de parentesco" (Michelena, 1969: 115). Foi assim como, a partir de conjeturas justificadas pela linguagem, procurou-se "reconstruir um estádio primitivo 'geral' da família basca" (Caro Baroja, [1956] 1976: 120).

Descontentes com os problemas analíticos derivados de procedimentos pouco rigorosos, e em paralelo aos usos políticos que o nacionalismo fazia des-
1 Todas as traduções deste texto (do espanhol, do euskera, do inglês e do francês) são de minha autoria.

2 O território culturalmente definido como Basco (Euskal Herria), localiza-se ao norte da Península Ibérica e consta de sete províncias divididas politicamente entre o Estado Espanhol e o Frances (três províncias na França, e quatro na Espanha). Três das províncias espanholas compõem a comunidade autônoma chamada propriamente País Basco (Euskadi) e a quarta abarca a totalidade de outra comunidade autônoma, Navarra. Existem, desse modo, duas demarcações daquilo que é considerado País Basco: uma política (Euskadi) e outra cultural ou identitária (Euskal Herria). Devido ao âmbito do problema que este artigo pretende levantar, no decorrer do texto sempre estarei me referindo à segunda acepção.

3 As especulações sobre a origem da língua basca são numerosas. A maioria das teorias afirma que o basco provem do ibérico ou do protourálico, algumas chegando a insistir em que é a "língua original de Europa" (Hamel e Vennemann, 2003); outras, ainda mais especulativas (e curiosamente as mais recentes) vinculam o euskera com o dogón (Mali) e falam de "semelhanças estruturais" relevantes (Efe, 2013). 
tes, a reação de vários autores desembocou na consolidação de uma antropologia local que se dizia modesta, despreocupada dos grandes debates internacionais e ocupada com catalogações folclóricas e extensas descrições das variações locais de uma suposta "tradição cultural basca"4 (Etniker, 2011), que, aparentemente, pouco ofereciam à teoria antropológica. No entanto, é precisamente na reavaliação dessa reação, ou desse caminho, que o debate ao que faço referência aqui (aquele que se debruçou durante mais de 60 anos numa analítica da "basquidade") tem a capacidade de oferecer uma revisão histórica de interesse que, em última instância, favoreça sua problematização no debate contemporâneo.

Neste artigo procurarei desenvolver um argumento epistemológico a partir da revisão da conflituosa relação que no decorrer do século $X X$ se desenvolveu entre ao que chamarei de antropologia da família basca e aquilo que, por motivos de economia textual, denominarei antropologia do parentesco mainstream ${ }^{5}$. O objetivo será oferecer uma pequena genealogia histórica dos métodos que participaram da produção da "família (tradicional) basca" como objeto antropológico e ressaltar sua problematização à luz de outros métodos. Para tanto, dividi o texto em três partes, três descrições históricas que procuram ressaltar diferentes diálogos entre teorias nativas e teorias gerais ou entre materiais locais e modelos antropológicos com diferentes escalas de compatibilidade.

Na primeira parte, descreverei o modo como, no começo do século $X X, 0$ País Basco foi objeto de um dos mais velhos debates em antropologia, decorrente da "premissa de Morgan de que os sistemas de parentesco correspondiam a vias de aceso direto às instituições" (Silva, 2001: 327). Analisando alguns argumentos desenvolvidos por antropólogos e linguistas na primeira metade do século XX será possível seguir certos problemas de compatibilidade entre os modelos teóricos de parentesco dos diferentes momentos históricos e a especificidade do material terminológico e etnográfico local. Minha hipótese consiste em assinalar que foi graças aos conflitos e reações sobre esses problemas de compatibilidade de modelos de parentesco que os antropólogos nativos foram gradualmente se aproximando ao conceito basco que define a casa e o grupo doméstico.

Na segunda parte focarei a atenção neste conceito: etxea. Tratarei de mostrar como já em alguns escritos antropológicos da primeira década do século XX a noção era citada como um paradigma que colocava em crise a aplicabilidade de determinadas teorias de parentesco ao contexto rural basco. Desse modo, será possível rever a gradual tomada de consciência que determinados antropólogos tiveram das relações que envolvem a casa e analisar os problemas e as constatações que surgiram derivadas desse fato.

Por último, proponho um deslocamento escalar: na terceira parte do artigo resumirei as estratégias metodológicas desenvolvidas por três autores -Fre-
4 O "Atlas Etnográfico de Vasconia" dos grupos de pesquisa Etniker, projeto de 15 volumes em constituição desde os anos 60 (dos quais já foram editados 6), pode servir como exemplo.

5 mainstream desenvolvimento histórico (de por si problemático e conflituoso) de determinados debates que marcaram decisivamente a narrativa geral da disciplina antropológica e que hoje são considerados fundamentais por exemplo, no seu ensino. 
eman, Schneider e Lévi-Strauss - quando enfrentaram problemas relativos à inadequação de conceitos teóricos em determinadas formas de organização social que mostram analogias com a lógica da casa basca. A presença destes autores é justificada por determinadas conexões comparativas feitas por eles ou pelos pesquisadores do País Basco citados nas duas primeiras partes do texto ${ }^{6}$. Desta maneira, estabelecerei um paralelo entre a etxea do País Basco, o bilek dos Ibam de Borneu (Freeman, 1958, 1961, 1970), o tabinau de Yap (Schneider, 1984) e as chamadas sociétés à maison (Lévi-Strauss, [1979] 1981, [1984] 1986, 1987) com o intuito de comparar métodos antropológicos (e não "sociedades", "sistemas de casamento" ou "culturas").

\section{A REAÇÃo AO “MATRIARCADO" DESDE OS TERMOS DE PARENTESCO EM EUSKERA}

Augustins (2000: 575) enumera três tipos de interpretação (combináveis uns com os outros) da terminologia de parentesco: como princípio de organização social, como regulação dos comportamentos e como sistema cognitivo autônomo. Por motivos que serão expostos no decorrer do texto, a interpretação mais influente nos estudos sobre a sociedade basca foi uma derivação direta da primeira, e que é possível atribuir a Lewis Henry Morgan.

Foi Morgan quem definiu as bases da antropologia do parentesco propriamente dita, "livre do campo gravitacional da história, do direito e da filologia" (Silva, 2010: 324). Decidido a comprovar certa conjectura evolucionista (foco das posteriores críticas mais duras feitas ao trabalho dele), em 1871, Morgan encontraria uma metodologia própria e um objeto especifico; vale lembrar: "As relações familiares são tão antigas quanto a família. [...] Um sistema de consanguinidade, que é fundado numa comunidade de sangue, é apenas a expressão formal e o reconhecimento dessas relações" (Morgan, 1871: 10). Assim, à procura de um esquema organizador de tais "expressões formais", Morgan proporia alguns conceitos essenciais, como a distinção entre "termos primários" e classes, que derivaria na famosa divisão entre "sistemas descritivos" e "classificatórios" (1871: 12). Sucintamente, os "sistemas descritivos" são aqueles nos quais "os colaterais e uma porção dos consanguíneos lineares de cada pessoa são descritos por uma combinação de termos primários" (1871: 42). Nos "sistemas classificatórios", no entanto, os consanguíneos "se organizam em grandes classes ou mesmo em princípios de discriminação peculiares às famílias" (1871: 143).

Ora, acompanhados desta brevíssima introdução ao pensamento teórico de Morgan, vale a pena se deslocar até o contexto basco e ler o seguinte, escrito pelo linguista Alemão Gerhard Bähr em 1935 acerca dos termos de parentesco em euskera:
6 Por exemplo, a presença de Freeman se deve a que autores como Douglass (1969, 1975) tenham relacionado diretamente teorias dele com o contexto basco. Do mesmo modo, existe um substrato analítico comum entre a teoria das "sociedades de casa" de LéviStrauss e pesquisas sobre o País Basco (Arpal, 1979; Caro Baroja, 1986; Marín-Paredes, 1998) a partir do estudo do parentesco feudal (Duby e Le Coff, 1977; Schmidt, 1957) e dos estudos relacionados ao conceito de "stem family" (Douglass, 1988; Fauve-Chamoux e Ochiai, 2009; Le Play, 1895; Todd, 1990). Outras conexões serão expostas no decorrer do texto. 
Não há distinção do parentesco duplo, (...) não há termos próprios para estas duas classes de antepassados [pai do pai e pai da mãe]. O avô é chamado de "pai bom", aiton, "senhor pai", aitajaun, "pai alto", aintagoi, ou "pai grande", aitahaundi. (...) Coisa curiosíssima, um homem velho só dispõe de um vocábulo para nomear quatro indivíduos diferentes de sua família; o neto, a neta, o sobrinho e a sobrinha. Seria lógico que esta surpreendente uniformidade tivesse sua raiz na constituição da primitiva família dos bascos (Bähr, 1935: 17/25).

Neste caso, a referência ao trabalho de Morgan não é explícita, embora seja óbvia. Segundo Bähr e outros autores da época, a não distinção dos termos - neto, neta, sobrinho, sobrinha-indica o vestígio de "um país com parentescos por classificação" (Aranzadi, 1913: 155), relacionando causalmente as terminologias do parentesco e os princípios de organização sociais passados e/ou presentes. Assim, a análise de outros termos cuja etimologia remete a línguas românicas, como kusu (derivado de cousin, primo) ou koinatu (derivado cognatum, cunhado), revelaria que "na antiguidade os bascos não teriam sentido a falta do termo para primo e prima" (Bahr, 1935: 27) e que "teria faltado um termo genuíno para cunhado pelas mesmas razões mencionadas a respeito do primo e o sobrinho" (Bähr, 1935: 31).

Se, para Bähr, o curioso é a falta desses termos dos quais dispõe um "homem velho", o que hoje resulta notável é que para ele tivesse passado despercebido o famoso artigo de Kroeber em que julgava "subjetivo" e "falacioso" ([1909] 1973: 15) tal ponto de vista e criticava duramente os que, como Bähr 26 anos depois dele, "ficaram impressionados com o fato de elas [as línguas estrangeiras] deixarem de discriminar certos parentescos entre os quais as línguas da Europa civilizada estabelecem distinções" (Koeber, [1909] 1973: 16). Não obstante, o alarmante desta situação não é a falta de cuidado, e de atualidade bibliográfica, de um dos autores mais considerados sobre o tema basco na época, mas o fato de ele estar refutando através dessa argumentação teorias ainda mais "extravagantes" (Bähr, 1935: 22)7. Um exemplo disto é que os escritos de Bähr estão abarrotados de referências críticas ao linguista Frances Vinson, que, mencionando a falta de um termo não emprestado do espanhol para definir a mulher virgem, teria dito que "os antigos bascos" desconheciam a virgindade, pois "não há dúvida de que para eles era um fato sem importância" (Vinson, 1908: 92).

Em essência, este enunciado de Vinson não é muito diferente daquele de Bähr. Salvando as diferenças, ambos parecem acreditar implicitamente que os termos de parentesco são uma chave de aceso para a compreensão de fatos sociológicos. No entanto, conforme Bähr, Vinson foi além:
7 No período que vai do início do século XX até o início da Cuerra Civil Espanhola, em 1936, o debate em torno dos nomes de parentesco em euskera mobilizou cartas, insultos e artigos entre pesquisadores de Espanha, França, Alemanha e Bélgica dedicados às mais diversas disciplinas: linguistas, antropólogos, arqueólogos e clérigos. O texto de Bähr precisa se contextualizar num diálogo diferente daquele mantido por Kroeber ([1909] 1973), Rivers ([1913] 1991), Lowie (1928), e Malinowski (1930) nesse período anterior a 1936. 
Segundo Vinson, em ambos [tio e tia (osaba e izeba)] encontra-se o radical aba, ou seja ama, "mãe", porque a família primitiva estivera baseada sobre a mãe. Desse modo, osaba e izeba deviam ter significado ambos "tia" exclusivamente. (...) É certo que, segundo opina Schrader, em indo-germânico primitivo os termos para tio materno e avô se confundiam, donde alguns eruditos concluem (seguramente equivocados) que nas tribos indo-germânicas prevalecia o matriarcado (Bähr, 1935: 22-23).

O ponto levantado por Bähr é importante. Grande parte das posteriores teorias do matriarcado basco ${ }^{8}$ serão um reflexo dessa argumentação acerca do sufixo ba (presente em vários termos de parentesco), que nunca chegaram a aprofundar na especulação de Vinson, mas que a assumiram como premissa e a consolidaram juntando a ela elementos trazidos dos estudos mitológicos (Aranzadi, [1981] 2000: 511). O debate propriamente antropológico, no entanto, continuou se articulando em torno dele por um tempo, focando várias críticas no uso ilegítimo que se fazia dos termos para tio e tia e chegando até a questão que envolve os termos aitaginarreba e amaginarreba (sogro e sogra). Assim, Telesforo de Aranzadi escreveu dois artigos em resposta a Vinson que foram determinantes para a posterior discussão, Da família basca inventada por Mr. Vinson (1911) e Cinarreba (Sogro) (1913). Neles, Aranzadi tentou fechar o assunto ridicularizando o autor francês e procurando recuar sobre as análises dos linguistas fazendo um chamamento de cuidado sobre os excessos da teoria e das grandes generalizações, ante os quais propunha certa moderação que ele acreditava encontrar no método antropológico. Nesses escritos de Aranzadi evidencia-se um primeiro ponto da hipótese que avancei na introdução e que diz respeito à reação dos antropólogos locais às teorias que procuravam ser aplicadas ao contexto basco. No entanto, os intentos por induzir teorias gerais através da terminologia do parentesco em basco continuaram, e só depois da publicação dois conhecidos artigos (Caro Baroja, [1956] 1976; Michelena, 1969) o assunto ficou, muitos anos depois, definitivamente resolvido (ou abandonado).

É conveniente fazer um breve esclarecimento a propósito dessa problemática que relaciona tios e sogros em basco antes de continuar. Caro Baroja, em seu artigo sobre a terminologia de parentesco, observou em primeiro lugar que em várias formas dialetais o termo em euskera que define o tio (osaba) é comumente utilizado para fazer referência ao sogro. Em segundo lugar, existem vários termos em basco para se referir indistintamente ao sogro e ao tio, concretamente aqueles "nomes que aludem ao parentesco espiritual entre padrinho, madrinha, afilhado e afilhada, que se valem de normas parecidas aos que servem para designar a avôs e netos, sogro e sogra" (1976 [1956]: 117-118). E, por último, encontram-se os nomes propriamente usados para designar sogro e sogra (aitaginarreba e amaginarreba), que:
8 A ideia do matriarcado é comumente relacionada a Bachofen. No entanto, no País Basco, especialmente no decorrer da segunda metade do século XX, ela tem um desenvolvimento próprio entre as pautas políticas nacionalistas com tendências autoproclamadas feministas ou de esquerda. Juan Aranzadi afirma que o "mito do matriarcado basco" é um dos tópicos antropológicos arraigado com mais força "entre os bascos atuais, já seja em sua versão forte, que postula a existência entre os antigos bascos de uma autêntica ginecocracia, de um verdadeiro poder da mulher sobre o homem, já seja em sua versão debilitada, matriarcalista, que entende o matriarcalismo basco não como uma improvável realidade bruta ou realidade objetiva impositiva, mas como uma estrutura psicossocial na que $o$ arquétipo matriarcalfeminino impregna, coagula e coliga o grupo social de um modo distintivo" (ênfases originais, [1984] 2000: 506). 


\begin{abstract}
Numa tradução literal (...) seriam "irmã do homem com a mãe" e "irmã do homem com o pai". A última parece um autêntico disparate. Masé preciso ter em conta que, no sistema de denominação de vários povos, determinados parentes mantém uma categoria sexual que não corresponde com seu sexo real. Esta categoria tem, segundo Radcliffe-Brown, grande significado estrutural desde o ponto de vista sociológico, que entre os bascos não encontro (ênfase minha, Caro Baroja, 1976 [1956]: 117).
\end{abstract}

Esta última frase é esclarecedora e essencial para o argumento que aqui apresento. Caro Baroja reconhece a possibilidade de arriscar a formulação de uma conclusão estrutural (no sentido inglês) que relacione o caso basco com outros paradigmas, mas recua. Ele foi discípulo dos pioneiros da antropologia no País Basco, Aranzadi e Barandiarán, e como eles (mais concretamente como o segundo), é "fiel (...) à escassez de interpretações" (Zulaika, 2000:119). Assim, o artigo finaliza com uma chamada de estilo boasiano à produção de "menos estudos reconstrutivos e mais análises histórico-culturais e funcionais do acontecido em épocas modernas ou melhor conhecidas" (Caro Baroja, [1956] 1976: 121). Contudo, não seria justo com a história da antropologia do parentesco se não mencionasse aquilo sobre o que Caro Baroja evitava meditar em 1956: a controvérsia do tio materno e o casamento entre primos cruzados, cujo traço geral é a ausência de termos distintos para os parentes por afinidade.

Caro Baroja era consciente de que a coincidência terminologia entre tio e sogro em euskera, somado às generosas interpretações que alguns anos atrás ele mesmo fez de determinados textos antigos que falavam sobre costumes de casamento na região ${ }^{9}$, permitia especular sobre um estado social historicamente precedente em que regras positivas de casamento entre primos cruzados estruturavam a "família basca". Tratar-se-ia da elucubração lógica a respeito de uma fase histórica na qual os bascos se considerariam parte daquilo que a antropologia conhece como sociedades elementares. No entanto, a inexistência de um correlato sociológico desta teoria (no País Basco não havia vestígios contemporâneos de casamento entre primos) desarmava o propósito indutivo, e insistir na questão levaria irremediavelmente a cometer um erro metodológico "consternador" (nas palavras de Lévi-Strauss), que, por exemplo, Rivers cometeu em $1907^{10}$.

Ressal to que o comentário de Caro Baroja procurava omitir uma extensa discussão de enorme relevância para a teoria antropológica desenvolvida na época. Vale lembrar que, depois de Rivers, Lowie (1919) e Radcliffe-Brown (1924, [1941] 1969) aprofundaram na questão do casamento entre primos, intensificando especialmente o debate sobre a correlação entre terminologia e sociologia (Dumont, 1975: 34), e que, graças à famosa proposição de Lévi-Strauss sobre a
9 Entre os quais se destaca o texto do século I a.C escrito pelo geógrafo Grego Estrabão, que menciona como "entre os cántabros (entre eles, os bascos) [registra-se] o fato de darem dote os homens às mulheres, e de deixarem herdeiras as filhas [e que] os irmãos sejam entregues em matrimônio às mulheres por aquelas [as herdeiras]: tinha, pois [o povo cántabro] uma espécie de ginecocracia" (Caro Baroja, [1943] 1973: 35). Ver Aranzadi, ([1981] 2000: 511-513 e p.519-521).

10 Lévi-Strauss o narrava deste modo: "A tentativa de Rivers (1907) de explicar a importância do tio materno no sul da Índia como um resíduo do casamento entre primos cruzados desembocava num resultado especialmente consternador: o próprio autor tinha que reconhecer que a interpretação não era capaz de dar conta de todos os aspectos envolvidos e se contentar com a hipótese de que vários costumes diversos e hoje desaparecidos (dos quais o casamento de primos era apenas um) teriam de ser invocados para compreender a existência de uma só instituição" (LéviStrauss, [1958] 2012: 69). 
"reciprocidade" e a "troca de mulheres" ([1949] 1982), o tema do avunculado se encontrava no centro dos debates antropológicos da década de 1950. A propósito disto, parece injustificado acreditar que em 1956 um autor atento como Caro Baroja deixasse passar inadvertidamente semelhante corpus teórico ${ }^{11}$.

Em definitiva, a hipótese que até aqui mantive é que determinados autores bascos, como Telesforo de Aranzadi e Caro Baroja, constituíram seus próprios argumentos antropológicos relativos à família basca a partir de uma série de reações a determinadas teorias gerais que procuravam implicar inadequadamente a realidade social local. Na próxima seção procurarei aprofundar estes argumentos. Desse modo, tratarei de estender essa hipótese demonstrando que foi graças a essas reações que Caro Baroja (precedido por alguns comentários de Aranzadi) se afastou gradualmente da ideia de família para se aproximar cada vez mais daquele conceito que em euskera define a casa e o grupo doméstico: etxea.

\section{ETXEA: A CASA COMO FAMÍLIA E A FAMÍLIA COMO CASA}

Um dos assuntos recorrentes no estudo das relações de parentesco no contexto basco é a falta de uma palavra específica em euskera para a definição do conjunto de parentes consanguíneos e afins, isto é, da família. Na atualidade, a palavra mais usada é o neologismo (emprestado do espanhol) famili(a), o que não supõe (ironizando sobre Vinson e Bähr) que os antigos bascos não soubessem da existência de parentes. No entanto:

No caso dos bascos é muito difícil na atualidade ded uzir unicamente da língua a forma de comunidade que era peculiar a estes e o vocábulo correspondente. É verdade que Azkue cita vários vocábulos que poderiam ser o caso: eroyalde, etxadi, leiñu, senikera, supizgu, aos que pode-se incorporar auzo. Mas estes significam caserío, linhagem, parentela, lar e vizinhança respectivamente (Bähr, 1935: 5).

É relevante observar que desses cinco termos possíveis atribuídos a Azkue três são relativos diretamente a definições territoriais ou espaciais, e, como mostrarei mais adiante, um quarto, linhagem, o será indiretamente. Procurando em um dicionário atualizado ${ }^{12}$, encontramos as seguintes definições:

FAMÍLIA: f.

- parentes: senitarte, familarte, etxekoak, senideak, arbasoak; como estáa família?: Zer moduz etxekoak?

- loc. Ter família: erditu, haurra izan, umea izan; em família: familian; ser da família: etxekoa izan.
11 Entre outros motivos porque o próprio autor fez alusão em diversas ocasiões a grande parte desse mesmo corpus. Por exemplo, em Sobre a casa, sua "estrutura", suas "funções" (Caro Baroja, 1969).
12 O dicionário utilizado é o "Adorez Hiztegiak-5000 hiztegia (euskera-castellanoy castellano-euskera)". Trata-se do dicionário do Governo Basco, Eusko Jaularitza, e pode ser consultado digitalmente na Azkue Fundazioa: http://www. bostakbat.org/azkue/. 
Neste caso foram introduzidas palavras de diferentes âmbitos. Senitarte e senide são termos relativos à germanidade (siblings). Senitarte resulta da fusão do enunciado senideen arte, literalmente, "entre irmãos", assim, os parentes não consanguíneos são comumente denominados ezkonsenideak, isto é, "irmãos de casamento". O mesmo serve para familarte, "entre familiares", e a primeira parte, famili(a), reafirma o dito anteriormente. Arbasoak significa, literalmente e segundo o mesmo dicionário, antepassados ou antecessores, e erditu, parir. Igualmente, ambas as conjunções haurra izan e umea izan significam "ter um filho" e "ter uma criança". Por último, encontra-se o termo sobre o qual quero fixar a atenção: etxekoak-etxe (casa)+ko (possessivo)+ak (plural), isto é, "os de casa".

É possível, agora, seguir o caminho inverso:

ETXE:

- casa em geral, albergue, habitação, quarto; kultura-etxea: a casa de cultura; postetxe: casa ou posto de correios; herriko etxea: a casa do povo; etxe-saila: quarteirão de casas; etxe-sartzea: entrada na casa. - casa (própria), lar; etxean ez du ardorik edaten: não bebe vinho em sua casa. - família; bere etxe guztiarekin etorri zitzaigun: veio com toda a família. - doméstico/ca: etxe-hegaztia: ave doméstica; etxe-aberea: animal doméstico. - familiar; etxe(ko) baratzea: horta familiar.

Não parece arriscado deduzir daqui que há uma relação particularmente intensa que une as noções de casa e de família em euskera. "Quando um basco se refere a 'nere etxea' ('minha casa') normalmente está se referindo a mais do que à habitação física" (Douglass, 1969: 87).

O complemento da hipótese que levantei anteriormente é que, se autores como Aranzadi ou Caro Baroja foram prudentes nas suas respectivas conclusões relativas aos termos de parentesco em euskera, foi porque algo não encaixava na tipologia familiar que tais nomes pareciam oferecer: a casa. É importante constatar como, em alguns dos livros e artigos interessados nos termos do parentesco em basco citados anteriormente, se encontram referências que denotam ceticismo sobre a metodologia em voga (o estudo da terminologia) e que manifestam indiretamente a possibilidade de outras linhas de análise. Aranzadi argumenta, em 1907, que:

O que a maior parte dos teóricos da família deixam de considerar, apesar de sua importância nesta questão, é que no País Basco como no Tirol o solar [a parcela vinculada à casa] é mais importante que o sobrenome patronímico, porque nele radicam os direitos. Alguns camponeses biscainhos se consideram quase parentes por ter casado com moças da mesma casa (Aranzadi, 1907: 599). 
Também Bähr, em 1935:

Na atualidade os irmãos solteiros permanecem na casa paterna, que chega a ser propriedade de quem casa primeiro. Segundo Aranzadi, este jeito de fazer as coisas é muito antigo e talvez o primitivo. Nesse sentido, se um pai não designava aos sobrinhos com um vocábulo particular, isto poderia ser porque não os conhecia ou os conhecia pouco, já que o irmão casado e a família deste residiam longe dele ${ }^{13}$ (ênfase minha, Bähr, 1935: 26).

Por outro lado, Caro Baroja escreve em 1944 Da Vida Rural Basca, uma das primeiras etnografias feitas no País Basco. Ele mesmo introduz o livro como o trabalho de um principiante, "mas também de um 'nativo' que seleciona temas (...); isto é, que vê o mundo que o circunda com olhos muito diferentes dos do 'doutorando' ou o professor que pertence a uma escola e aplica os seus métodos", e se declara contra aqueles que se dedicam a "fazer generalizações, partindo de experiências distantíssimas, sem ter em conta os fatos próximos" e a "observar em função de teorias, ou mais que teorias, de opiniões e esquemas" ([1944] 1974: 16-17). Seguido de tais declarações dedica a primeira das três partes do livro à casa e ao caserío (casa rural, chamado baserri em euskera), às formas de propriedade e arrendamento da mesma e a questões relativas ao trabalho doméstico. Já na segunda parte, reflete indiretamente sobre a família. Para tanto, desenvolve a análise em mais três subitens, que podemos definir como (1) vizinhança, (2) da infância ao matrimônio e (3) do matrimônio à morte. Mais adiante ficará evidente a razão desta divisão, já que o matrimonio é o momento da transmissão hereditária troncal da casa de um casal proprietário (etxejabeak) ao seguinte geracionalmente. Pelo momento, meu propósito é ressaltar como certa intuição neste trabalho prematuro de Caro Baroja (que o autor admite como tal) o leva a contornar o objeto etnográfico de um modo certamente distante daquele comentado antes a propósito do circuito teórico internacional. Em nenhum momento se faz referência a termos de parentesco ou a genealogias; o autor se contenta em falar de relações que envolvem a casa.

Depois disso, Caro Baroja continuou prestando atenção à casa (1969; [1949] 1971: 25-132; [1957] 1986: 181-233) até a culminação naquilo que ele mesmo considerou sua "obra mais original e intensa" (Ridruejo, 1983): A Casa em Navarra (1982). Em paralelo, é preciso assinalar que, depois dele, praticamente todas as etnografias feitas no meio rural basco insistiram direta ou indiretamente na centralidade da casa como reguladora das relações do grupo doméstico e do sistema econômico (Greenwood, 1976; Ott, 1981; Zulaika, 1990). Além disso, Douglass $(1969,1975)$ indicou que é o caserío (baserri) e não a atividade do grupo doméstico a unidade sobre a qual o sistema de vizinhança rural (auzoa) se
13 Não é meu objetivo neste artigo desenvolver a questão das implicações do gradiente de distância nos sistemas cognáticos, tema que no estudo das sociedades ameríndias foi especialmente fecundo (para uma síntese, ver Viveiros de Castro, 2005: 87-180) e que, no caso basco, é reconhecível como um caminho interessante para a análise da relação entre afinidade e consanguinidade. Afirma Viveiros de Castro que "a distinção entre o próximo e o distante é característica de socialidades onde a residência predomina sobre a descendência, a contiguidade espacial sobre a continuidade temporal, a ramificação lateral de parentelas sobre a verticalidade piramidal de genealogias" (2005: 130) Nesse sentido, considero justo constatar o potencial deste comentário de Bähr, ignorado até hoje. 
articula, e que "quando uma família abandona uma casa e uma nova chega, esta assume o lugar da anterior na rede de obrigações vicinais ditadas pela disposição espacial" (1975: 69). Parece ser que, no País Basco, "a estrutura física da casa domina sobre outras muitas possíveis funções da família e do trabalho" (Caro Baroja, 1969: 58), e que a geografia e a distribuição dos assentamentos "são fatores decisivos na caracterização de cada casa como uma constelação de moradia, mobiliário, material agrícola, patrimônio e espaço de sepultura" (Douglass, 1969: 87) relacionada simultaneamente a outras mediante diferentes redes de práticas, alianças ou rituais que cada grupo doméstico é obrigado a manter (Douglass, 1975: 70).

Por outro lado, na maior parte do meio rural basco, as casas têm nome próprio. "Basagoiti" (alto do bosque), "Rekalde" (junto ao córrego), "Zubiaurre" (frente à ponte) ou "Ormaetxea" (casa de muros) são exemplos de nomes destes caseríos; nomes que descrevem ou localizam a casa e, ao fazê-lo, identificam o grupo social, a família, que nela habita e cujo nome não é necessariamente compartiIhado. São vários os estudos de onomástica (Mitxelena,1969, 1989) e oiconímia (Apezetxea, 1985, 2007; Ariztegi, 2000; Ibarra Murillo, 2002, 2003) que vêm insistindo em que é a família a que toma o sobrenome da casa, e não o contrário (Mitxelena, 1989: 10).

As etnografias posteriores ao trabalho de Caro Baroja insistiram em que a "família rural basca" depende da etxe para ser nomeada e identificada socialmente; ainda mais, política e juridicamente, supostamente de forma generalizada até o século XX, era a casa e não seu proprietário (etxejabea) quem se assumia como sujeito das obrigações coletivas e das cargas econômicas (Ezquerra, 1994: 7). Historicamente (decretado juridicamente em Biscaia desde o "Fuero Viejo" de 1480), a descendência cognática, caracterizada pela herança troncal do caserío e de todos os bens materiais da família para um único descendente (homem ou mulher) "livremente escolhido", perpetuava algo análogo a uma linhagem familiar (Arrizabalaga, 2002: 38; Aranzadi, 2001: 901; Caro Baroja, 1969: 49; Ezquerra, 1994: 28). Esta pessoa, o etxekojauna (senhor da casa) ou a etxekoandrea (senhora da casa), era escolhida por sua capacidade para manter o equilíbrio doméstico e por seu interesse e participação nos assuntos da casa. Ela tomava o mando do baserri junto com seu afim (que adquiria o sobrenome da nova família, isto é, o nome da casa) a partir do casamento. Desse modo, os senideak (siblings) não herdeiros tinham direito a ficar na casa até o matrimônio, momento em que podiam formar um novo grupo familiar (com um novo sobrenome) através da construção de uma nova casa ou podiam se incorporar à de um afim herdeiro, por sua vez, de outra casa (Aranzadi, 2001: 902).

A partir daqui a antropologia local consolidaria a definição da "família basca" como etxekoak (os de casa): unidade doméstica formada pelo casal principal 
(etxejabeak), seus descendentes e os colaterais solteiros (mutil zaharrak e neska zaharrak) e ascendentes do/a unigênito/a (Douglass, 1975: 17). Outros, como filhos bastardos ou pessoas adotadas ou em relação de dependência, eram comumente incorporados ao grupo doméstico e considerados também etxekoak, sempre que mantivessem o celibato (Aranzadi, 2001: 903).

Em comparação aos conflitos teóricos assinalados na primeira parte deste texto, as perspectivas que abriam estas novas constatações etnográficas no decorrer da segunda metade do século XX pareciam antecipar um futuro analítico menos ideológico e mais sensível às particularidades que o campo reclamava ${ }^{14}$. Contudo, alguns intentos por explicar a questão da filiação e da afinidade de um suposto "parentesco basco" continuaram. A lógica familiar descrita acima foi tratada em várias ocasiões a partir de uma ótica histórica que pretendia ver nela um reflexo às vezes excessivamente estrito das relações familiares feudais (Aranzadi, [1981] 2000, 2001; Arpal, 1979). Assim, movimentando conceitos do passado para o presente procurou-se explicar a estrutura da família como o derivado dos chamados parientes mayores, isto é, dos senhores da guerra que, entre os séculos XIV e XVI, dominaram os territórios do País Basco. Estas figuras supostamente agnáticas ${ }^{15}$ consolidavam o parentesco desde certa unidade moral que vinculava estritamente a linhagem paterna e a casa-solar (Caro Baroja, 1986: 13-61), numa lógica que permitiu comparações com a teoria dos grupos de unifiliação da antropologia social britânica e mais concretamente com Leach, que advogaria pela importância dos conceitos de "propriedade" e "territorialidade" dos "grupos de filiação local" (Leach, 1951; 1962: 214), "isto é, da parte de um grupo de unifiliação que, pelo fato de residir num mesmo lugar, é suscetível de atuar de forma coletiva, como um grupo mais ou menos corporate" (Dumont, 1975: 127).

Por um momento, seguindo este raciocínio, a questão basca pareceria se adequar a uma teoria antropológica mainstream. A explicação teria um fundamento histórico importante, a chamada "Fidalguia Universal" (Aranzadi, [1981] 2000: .440-449): o reconhecimento por parte do rei de Espanha em 1527 de que todos os biscainhos e guipuscoanos (os habitantes de duas das províncias que compõem o País Basco) eram nobres (Soria Sesé, 2006: 284), acontecimento que teria levado à extensão das práticas nobiliárias sobre a família ao resto da população rural (Aranzadi, 2001: 889). Um único aspecto nada irrelevante ficaria por explicar, que, como já comentei acima, tanto nos séculos XIV, XV e XVI (Marín Paredes, 1998; Oliveri Korta, 2001, 2009) quanto na atualidade, a descendência não é unilinear, mas cognática, isto é, que o pilar de semelhante edifício teórico, a filiação, não tem cimentação.

Espero ter evidenciado nestas duas seções que, apesar de se explicitar irregularmente, a interdependência entre a antropologia da família basca e as teorias
14 Considero imprescindível assinalar que neste artigo não procuro esgotar toda a bibliografia existente sobre o problema do parentesco nas regiões bascas. Como assinalei na introdução, meu recorte delimitou alguns autores que assumiram de algum modo a "família basca" como objeto analítico ou que forneceram dados etnográficos que contribuíram para sua formação categórica. É conveniente citar, nesse sentido, trabalhos de antropologia do parentesco ou da família que, nos últimos 40 anos, lidaram com aspectos que envolvem o País Basco, mas que não isolaram analiticamente a região; seja desde o ponto de vista do âmbito dos Pirineus (Augustins, 1989; Lison Tolosana e Ozanam, 1986), do Mediterráneo (Peristinay, 1987), da Europa (Goody, 1983. 2000; Porqueres i Gené, 2007) ou da Espanha e do norte da Península Ibérica (Chacón e Bestard, 2011; Pina-Cabral 1991).

15 Cabe dizer que estudos históricos contemporâneos demostraram que também nos séculos XIV e XV o parentesco dos "parentes maiores" era cognático, e que implicava relações incessantes com a casa (Marín Paredes, 1998; Oliveri Korta, 2001, 2009). 
internacionais foi decisiva para o desenvolvimento das análises que até hoje se fizeram do material etnográfico basco. Contudo, é conveniente deixar aqui esta discussão para passar a outros casos melhor conhecidos pela antropologia mainstream, de maneira que seja possível encontrar novas analogias que nos permitam acentuar o objetivo último deste artigo, que diz respeito à análise de procedimentos metodológicos em relação a um dado objeto antropológico.

\section{DA TERMINOLOGIA DO PARENTESCO BASCO À TERMINOLOGIA DA ANTROPOLOGIA DO PARENTESCO: "UTROLATERAL", "SOCIETÉ À MAISON" OU SIMPLESMENTE ETXEA?}

Murdock, em seu ambicioso intento por representar e classificar "todas as culturas conhecidas pela historia e a etnografia", publica em 1957 um novo artigo no qual expõe uma extensa tabela que fraciona 565 sociedades em 15 "categorias etnográficas standard" (1957: 664). A categoria que me interessa aqui, chamada por ele "residência marital", é dividida em 14 complexos termos que procuram dar conta de todas as possibilidades relativas à questão ${ }^{16}$. Os Bascos, assim, são etiquetados como "Bn" (1957: 677), isto é, com um sistema de residência que combina a "neolocalidade" com a "bilocalidade", o que significa que "matrilocalidade ou patrilocalidade acontecem com a mesma frequência" (1957: 670).

"Bilocal" era já o termo proposto por Murdock (1949: 16) para substituir outra palavra que mencionava ter sido usada por alguns autores com anterioridade para descrever a mesma regra: "ambilocal"17. Contudo, Barnes, por sua vez, levantou alguns problemas relativos aos termos "ambilocal" e "bilocal" (este ultimo ocasionalmente usado por Hogbin e Wedwood com um significado diferente ao de Murdock) e propôs o termo "utrolocal" como substituto de ambos (1960: 852). O próprio Barnes explicitava que a eleição de tal palavra fazia referência a outro termo, "utrolateral", que Freeman tinha proposto cinco anos atrás.

Desconheço se este conflito, mais semântico que propriamente antropológico, continuou nos anos seguintes nesse mesmo sentido. Desconheço, desse modo, qual é o neologismo oficializado pela teoria do parentesco que na atualidade descreve com mais rigor o tipo de regra de residência marital que predomina no contexto rural basco. O que quero ressaltar aqui é a particularidade de um debate localizado num nível epistemicamente distinto (não necessariamente superior) daquele que ocupa o terreno da descrição etnográfica. É preciso dizer, no entanto, que quando Freeman propôs o termo "utrolateral" estava tentando classificar aquilo que estava vendo entre os Iban de Bornéu:

Na sociedade Iban não há semelhança com qualquer sistema de filiação ("descent") segmentário com linhagens e clãs; em vez disso, como já descrevi detalhadamente em outro lugar (Freeman, 1958), o único grupo de parentesco corpo-
16 Estes são: Avunculocal, Bilocal, Duolocal, Matrilocal, Neolocal, Patrilocal, Duopatrilocal, Sororilocal, Uxoripatrilocal, Uxoravunculocal, Uxorineolocal, Uxoribilocal, Viravunculocal e Duoavunculocal (Murdock, 1957: 670).

17 Murdock não cita tais trabalhos, mas, em outro lugar, Needham comenta como Firth tinha proposto o termo "ambilateral" para descrever o hapu Maori (Needham, 1956: 148), cuja regra de residência marital parece similar. 
rado entre os I ban é a família bilek, cujos membros possuem e ocupam um dos apartamentos de uma "long-house". A continuidade da família bilek é assegurada por um sistema de unifiliação "utrolateral": em cada nível geracional pelo menos uma das crianças da família (podendo ser filho ou filha) continua como membro da residência familiar, e dessa forma, o bilek, com um estado sobre o qual os membros residentes têm direitos de herança em comum, persiste de uma geração para outra (Freeman 1961: 211).

Esta pequena descrição do bilek parece suficiente para constatar certa semeIhança com o anteriormente descrito acerca da etxea basca ${ }^{18}$. Alguns detalhes do fragmento assinalam a particularidade de um sistema que não pode se reduzir à catalogação da residência marital, já que envolve elementos de corporação definidos por uma estrutura material (a casa física) e sua perpetuação por meio de determinado tipo de herança e transmissão. Nesse sentido, resulta evidente a perda de informação que tem lugar quando a definição de "utrolateral" se encontra isolada ${ }^{19}$ :

Com o termo "utrolateral" (...) proponho designar um sistema de descendência em que um indivíduo pode pertencer ao grupo de nascimento do pai ou da mãe, mas não de a mbos ao mesmo tempo (Freeman, 1958: 27).

Na lógica da etxe, e talvez também do bilek (se temos em conta a bilateralidade dos Iban), a descendência não é relativa a uma "pertença" absoluta a um dos grupos, mas, como menciona Douglass, a uma "ênfase" (1969: 103). Trata-se de coabitar com um dos grupos, mas não de uma pertença de sangue que exclui o outro. Acredito, nesse sentido, que Freeman evita intencionalmente acompanhar tal definição da palavra linhagem, mas não esclarece de imediato que a descendência é cognática (deixa que o exemplo etnográfico dos Iban cumpra tal função), o que pode levar a confusões desnecessárias ${ }^{20}$.

Por outro lado, em seu artigo de 1960, Freeman demonstrou ter plena confiança na afinação e padronização do vocabulário da antropologia do parentesco. Seguindo as variações que historicamente se fizeram do termo "kindred", propôs uma definição (legitimada pelo significado jurídico que ele considerou originário da palavra) que fechasse o assunto e aproveitou para reafirmar a relevância do termo "utrolateral". O argumento dele nessa conexão, resumidamente, se basearia na importância dos primos (e do matrimônio entre estes, às vezes permitido e inclusive preferencial) no processo de cálculo (por um ego específico) das possibilidades e impossibilidades de casamento nas sociedades cognáticas. Para ele, a extensão do reconhecimento "seletivo" de primos (chegando em ocasiões até o quinto grau) "não lidaria com uma relação genealógica demons-
18 Analogia originalmente feita por Douglass $(1969,1975)$

19 Também numa definição recente, extraída de um dicionário de antropologia: "Utrolateral: termo de parentesco acunhado por Derek Freeman como oposto à ambilateralidade: os direitos utrolaterais são reivindicados via uma linha parental, mas não por ambas" (Morris, 2012: 262) 
trável, mas com uma suposta cognação" (Freeman, 1960: 207) que estabeleceria limites sociológicos. Consistiria, pois, na ativação, por parte de um indivíduo, de uma rede de classificação de cognatos que atravessaria as unidades propriamente exógamas de "grupos corporados" (neste caso, a casa), o que ajudaria na estruturação da afinidade.

Vale dizer que estas considerações proporcionam um modelo explicativo para a anteriormente descrita controvérsia dos termos de parentesco em basco bastante menos arriscado que a teoria do avunculado. Assim, não é estranho que Douglass se interessasse pela questão dos "kindred" no contexto rural basco (1967: 166-189), chegando a mencionar o trabalho de Freeman e estabelecendo uma analogia entre o bilek e a etxea (1967: 103). Contudo, a descrição etnográfica de Douglass, interessada nos detalhes e particularidades do caso de Murelaga (pequena localidade rural do País Basco), parece desestimar o potencial analítico do termo "utrolateral", que apenas é citado como uma singularidade acadêmica (1967: 103).

O que aqui quero constatar é que a estratégia metodológica de Freeman, frente à problemática de um caso de estudo difícil de classificar para a teoria de parentesco vigente nos anos 50, se baseou na confiança no aperfeiçoamento do vocabulário da antropologia do parentesco, que pretendia preservar e consolidar. No entanto, apesar de suas pretensões, o termo "utrolateral" não teve maior influência nos estudos antropológicos posteriores ${ }^{21}$. Freeman foi respeitado como etnógrafo por seu trabalho entre os Iban, e ficou famoso pela controvérsia que anos depois ele mesmo provocou sobre o trabalho de Margaret Mead (Freeman, 1983), mas sua contribuição terminológica caiu no desuso próprio do exemplo curioso.

Por outro lado, um dos poucos que no final da década de 70 ainda lembrava-se do termo de Freeman era Lévi-Strauss. Em um de seus estudos sobre a casa, numa breve menção à proposta de Freeman, Lévi-Strauss fazia uma definição de "utrolateral" completamente distinta das do seu inventor:

A incorporação dos filhos à família junto à qual, no momento de seu nascimento, seus dois pais escolheram residir, por livre decisão e também em resposta às pressões provindas de ambos os lados. (Lévi-Strauss, [1984] 1986:190)

Cabe dizer que tal definição parece estar encaminhada exatamente no sentido contrário (desde um ponto de vista metodológico) das anteriores; se o interesse de Freeman era a proposição de um termo que amplificasse a classificação de determinado tipo de relações também presentes em outras sociedades (o que o levava a cair num excesso de ambiguidade que dava pé a confusões), o excesso de concreção em relação ao caso Iban da definição de Lévi-Strauss parece levar à
21 Já foi mencionado como Douglass decidiu não aproveitar o termo (1967: 103) e Needham o criticaria duramente (1956: 148). Um terceiro exemplo é a coletânea de artigos "em honra de Derek Freeman" editada por Appell e Madan, na qual o termo "utrolateral" apenas é mencionado em uma ocasião (1988: 8) como um aspecto menor da obra deste (a pesar de ter ocupado um espaço preeminente nas publicações dele na década posterior a 1955). 
exclusão de parte de tais casos etnográficos. Nesta conjuntura, quem pretendesse dar conta do caso basco a partir do termo "utrolateral" teria que escolher entre a perda de informação da definição de Freeman e a inadequação da definição de Lévi-Strauss, já que as particularidades da eleição da residência no contexto basco são outras às mencionadas por este último. De qualquer modo, o interesse de Lévi-Strauss, mais uma vez, não estava no potencial analítico do conceito de Freeman, mas nas características do bilek dos Iban, que encaixavam na definição das sociètès à maison; conceito que o francês desenvolveria nos anos 80 ([1979] 1981, [1984] 1986, 1987) na procura de princípios explicativos para as estruturas de parentesco "semi-complexas", nas quais "o problema" se encontra na "integração de uma linhagem agnática e de um parentesco cognático" (Lévi-Strauss, [1984] 1986: 200).

Lévi-Strauss desaprovava que Freeman (entre outros antropólogos interessados em Bornéu) tivesse colocado "o princípio organizador das sociedades cognáticas ou na filiação, ou na propriedade, ou na residência” ([1984] 1986:189), e aproveitou o impulso desta crítica para propor a aliança como o princípio essencial das relações que envolvem a casa, já que "tanto em Bornéu como em Java, o casal conjugal forma o verdadeiro núcleo da família e, de modo mais geral, do parentesco" ([1984] 1986: 190). A definição da "noção de casa" que acompanhava esta argumentação é hoje clássica:

\section{Pessoa moral detentora de um domínio composto simultaneamente por bens} materiais e imateriais e que se perpetua pela transmissão do nome, da fortuna e dos títulos em linha real ou fictícia, tida como legítima sob a condição única de esta continuidade poder exprimir-se na linguagem do parentesco ou da aliança e, as mais das vezes, em ambas ao mesmo tempo (Lévi-Strauss, [1979] 1981: 154).

Os exemplos etnográficos que, por sua vez, acompanhavam tal definição não se limitavam a um marco espacial ou temporal, alguns destes eram os Kwakiutl da Colúmbia britânica ([1979] 1981:143, [1984] 1986: 185), os Iban e os Rungus de Bornéu, os Karo Batak de Sumatra, os Atoni de Timor, os Itsekiri do Niger ([1984] 1986: 191-225), etc. Os bascos não foram citados por Lévi-Strauss, porém, o caso das casas medievais e as famílias nobres da Europa feudal foi colocado por ele como uma referência importante ( [1979] 1981: 156-167, [1984] 1986: 186), o que nos poderia levar de volta àqueles trabalhos sobre o País Basco interessados em mostrar a continuidade do tipo familiar feudal no contexto rural contemporâneo (mencionado na seção anterior) ${ }^{22}$.

Devo explicitar que Lévi-Strauss não partia, como Freeman, da incorreção classificatória de um caso de estudo concreto ao qual quisesse dar explicação. Sua contribuição se encaixa num ambicioso projeto antropológico que teria

22 Outra conexão pode se fazer através do conceito de "famille-souche" ou "stem Family" desenvolvido por Le Play (1895) e relacionado abertamente às considerações de Lévi-Strauss sobre as sociedades de casa (Fauve-Chamoix e Ochiai, 2009). Foi o próprio Le Play quem colocou o País Basco como exemplo do conceito (Le Play, 1895: 40-44), promovendo uma classificação que até hoje é usada (Douglass, 1988; Todd, 1990). 
começado com As estruturas elementares de parentesco ([1949] 1982) e que procurava uma trilha conceitual mais ou menos homogênea que envolvesse as sociedades elementares e as complexas. Não é de estranhar, nesse sentido, a miríade de exemplos etnográficos (de America do Norte, Europa, Melanésia, Polinésia e África) que ocupam a base do argumento, comprovando empiricamente, e a cada instante, a adequação do conceito de casa ao modelo do analista ${ }^{23}$. Ademais, pode-se dizer que Lévi-Strauss estava, simultaneamente, indo um pouco além, pois na adequação do conceito de casa a cada caso etnográfico estava reformando (readequando) a teoria da aliança, chegando a "uma versão menos determinista e regrada do seu estruturalismo" (Carsten e Hugh-Jones, 1995: 9).

Espero ter deixado claro que meu interesse, neste momento, não é ressaltar as possibilidades que o exemplo basco teria fornecido ao conceito de Lévi-Strauss. Também não pretendo ressaltar as consequências e problemas de uma eventual "aplicação" do conceito no contexto basco; considero que a coletânea de Carsten e Hugh-Jones (1995) é de certo modo um aviso dos perigos analíticos os quais pode enfrentar quem empreende tal tarefa. Como tentei fazer com Freeman, meu interesse está em indicar o tipo de estratégia metodológica implícita no fundo do conceito de sociétés à maison.

Na mesma época em que Lévi-Strauss propunha a teoria mencionada, em 1984, Schneider iniciava sua controvertida "crítica ao estudo do parentesco", baseando-se nos problemas descritivos derivados de um "uso defeituoso da teoria do parentesco" (1984: 38) sobre a lógica social na ilha de Yap (no Pacífico ocidental). $\mathrm{O}$ argumento de Schneider tomava como ponto de partida a comparação de duas descrições da "organização social" dos yapeses desenvolvidas por ele mesmo em épocas distantes; uma primeira extraída da tese de doutorado dele (no final dos anos 40) e escrita segundo "a erudição convencional sobre o estudo do parentesco" da época (1984: 6), e uma segunda, contemporânea à publicação do livro, escrita segundo a "procura das concepções, formulações e definições nativas" (1984: 75) que "não pressuponham a noção de parentesco" (1984: 6). Assim, a contraposição das duas descrições deriva na demonstração de uma confusão analítica na primeira descrição que tergiversa o sentido de vários conceitos nativos e do sistema organizacional como um todo. Dentre estes conceitos, me interessa ressaltar um: o tabinau.

Na primeira descrição de Schneider, o tabinau se mostra simultaneamente como (1) uma família extensa patrilocal, isto é, uma unidade doméstica "que inclui as esposas que entram pelo casamento e exclui as filhas e irmãs que saem", e como (2) uma linhagem patrilinear marcada por estritas regras de sucessão, que inclui as filhas e irmãs que saem e exclui as esposas que entram (Schneider, 1984: 11):
23 Schneider argumentaria, a propósito de Lévi-Strauss, que "[a] estrutura não é inerente à constituição concreta de qualquer sociedade particular, mas o é ao 'modelo' ou o construto que deve ser desenvolvido pelo antropólogo quando pretende entender tal sociedade" (Schneider, [1965] 2011: 457). 
De acordo com a primeira descrição os membros de um tabinau são um homem e sua irmã, seu filho e filha, seu filho do filho e filha do filho, e assim por diante para cima e para baixo numa patrilinhagem, de maneira que a definição do tabinau por sua orientação para um antepassado faz dele um grupo de filiação (“descent") (1984: 35).

Na segunda descrição, o tabinau é uma "unidade cultural" polifacetada que faz referência à casa ou à moradia e que envolve pessoas através de laços territoriais. Cada tabinau tem nome próprio e é mediador na nomeação dos indivíduos que agrupa e os quais são incorporados não por condicionantes de nascimento, mas pela satisfação permanente de determinadas obrigações. Ao redescobrir o conceito de genung, que invoca propriamente as relações de consanguinidade por via materna e que era funcionalmente depreciado na primeira descrição, Schneider percebe que o tabinau não é uma "unidade territorial corporada" e conclui que a agnação não é "culturalmente significante" em Yap (1984: 21-36).

Em definitiva, "na primeira descrição (...) o tabinau é parentesco (patrilinhagem), na segunda descrição, tabinau é tabinau" (Machado, 2013: 52). Esta diferença conceitual, cuja razão é metodológica, é essencial para o argumento que procuro seguir. O que Schneider propõe é que, no estudo de uma determinada sociedade, o fazer etnográfico desenvolva sua argumentação desde ela mesma, desde seu "idioma" e seus "princípios ordenadores" (Schneider, 1984: 52), e não desde os mecanismos tautológicos (diria Bateson) do conhecimento consolidado da antropologia do parentesco. A estratégia de Schneider parece desenvolver um enfrentamento catártico; através da autoanálise (do trabalho dele e do contexto teórico em que esteve imerso por anos) procura a libertação do procedimento etnográfico das "propensões etnocêntricas" (1984:145) da antropologia do parentesco. Atrevo-me a falar, desse modo, que o que ele pedia não é muito diferente daquilo que Caro Baroja acreditava fazer no contexto basco quando se apresentava como aquele "nativo que seleciona temas" e que "vê o mundo que o circunda com ol hos muito distintos aos do 'doutorando' ou o professor que pertence a uma escola e aplica seus métodos" ([1944] 1974: 16). De fato, o que levou ambos até semelhante dilema foi a reação ante um problema análogo, relativo à incorreção classificatória de dois conceitos, o tabinau e a etxe.

\section{CONCLUSÃo}

Cada qual retém seu próprio "carácter"-sua própria organização do universo apercebido-, e, no entanto, é óbvio que algo aconteceu. Pautas de interação foram geradas ou descobertas, e estas pautas têm perdurado, pelo menos por um breve lapso. Dito de um outro modo: teve uma seleção natural de pautas de inte- 
ração. Algumas delas sobreviveram mais que outras. O que se produziu, então, foi uma evolução do ajuste mútuo (Bateson, [1979] 2011, p.153).

Neste artigo, pretendi mostrar em primeiro lugar como a progressiva atenção que foi se dando no decorrer do século $X X$ ao conceito basco que vincula casa e família, etxea, não foi o produto direto de uma teoria positiva propriamente nativa, mas o derivado de uma reação sobre o debate mainstream da teoria antropológica, que, durante várias décadas, localizou-se no âmbito da terminologia do parentesco. No mesmo sentido, ao procurar estabelecer um paralelo com as diferentes estratégias teóricas de Freeman, Lévi-Strauss e Schneider em torno a problemas com certas analogias com o apresentado no contexto basco, quis levantar uma questão epistemológica que leva em consideração a importância do trabalho sistêmico da disciplina antropológica. O pequeno percurso da antropologia do parentesco no País Basco aqui resumido é uma ínfima parte de um projeto aberto e sem limites reconhecíveis, que perpetua seu sentido através de uma constante oscilação. Acredito que Bateson se referia a este mesmo procedimento quando falava de "processos mentais" ou "espirituais" ([1979] 2011: 103, [1972] 1998: 432); totalidades constituídas na imanência da interação combinada de partes diferenciadas ([1979] 2011: 104) capazes de finalidade e eleição através de processos autocorretivos (([1979] 2011:141) que produzem mudanças "para manter a verdade de algum enunciado descritivo, algum componente do statu quo" ([1972] 1997: 460). Podemos pensar, por exemplo, que a crítica iconoclasta de Schneider foi precisamente o fenômeno autocorretivo da antropologia do parentesco? No final das contas, hoje alguns reconhecem o papel reformador que o trabalho dele assumiu: "querendo matar o parentesco, Schneider conseguiu ressuscitá-lo" (Machado, 2013: 108).

O certo é, então, que a antropologia sobre o País Basco a que aqui fiz referência, relativamente ignorada pela teoria internacional, nunca esteve efetivamente desligada desta; nunca foi autônoma (como em algum momento Caro Baroja pretendeu). Nas entrelinhas das intermináveis descrições folclóricas dos discípulos de Barandiarán subjaz um fundo aparentemente indiferenciado que atualiza a totalidade dos conflitos teóricos passados. No entanto, o que aqui propus não foi reinvocar tais fatos perdidos no fluxo da prática antropológica, mas retroalimentar esse mesmo fluxo com os elementos dispersos e em ocasiões problemáticos que a modesta antropologia local soube produzir (pois se trata de elaborações, $e$ não de descobrimentos). Perturbar mais uma vez o sistema, e ficar à espera que as possibilidades extraídas da colisão ofereçam a direção do seguinte passo.

Como adiantei na introdução, procurei oferecer uma síntese histórica dos métodos que participaram da definição de um objeto antropológico (a "família basca") e salientar sua problematização desde uma análise comparativa com ou- 
tros métodos. Como numa pintura cubista, num movimento inverso daquele que pretende a consolidação da aparência de um objeto através de uma determinada perspectiva, meu propósito foi abrir o objeto à análise de alguns dos seus olhares.

Ion F. de las Heras é Graduado em Arquitetura e Urbanismo pela ETSAB-UPC, Mestre em Antropologia Social pelo PPCAS-UFSCar e Bolsista da Fundação de Amparo à Pesquisa do Estado de São Paulo (Fapesp, Processo 2014/19818-6).

\section{REFERÊNCIAS BIBLIOCRÁFICAS}

APEZETXEA, Pello

1985 "Etxalarko etxe eta baserrien Izenak (1625-1983)".

Fontes Linguae Vasconum, n.45: 183-203.

APPELL, George N. e MADAN, Triloki N.

1988 Choice and Morality in Anthropological Perspective: Essays in Honor of Derek Freeman. Nova York, State University of New York Press.

2007 "Etxalarko etxeak". Fontes Linguae Vasconum, n.104: 67-140.

ARANZADI, Juan

[1981] 2000 Milenarismo Vasco. Edad de oro, etnia y nativismo. Madrid, Taurus.

2001 "Raza, linaje, familia y casa-solar en el País

Vasco". Hispania, LXI/3, n.209: 879-906.

ARANZADI, Telesforo de

1907 "Problemas de etnografía de los Vascos". Revista Internacional de Estudios Vascos (RIEV), vol. I: 565-608.

1911 "De la familia vasca primitiva inventada por Mr. Vinson". Euskalerriaren Alde, n.15: 453-458.

1913 "Cinarreba". Revista Internacional de Estudios Vascos, (RIEV), vol. VII: 154-157.

ARIZTEGI, Andrés I.

2000 "Nombres de oficios en la oiconimia navarra".

Fontes Linguae Vasconum, n.83: 139-149. 
ARPAL, Jesus

1979 La sociedad tradicional en el Pais Vasco. Zarautz, Itxaropena.

ARRIZABALACA, Marie-Pierre

2002 "Les Héritières de la maison au Pays Basque du

XIXe siècle". Lapurdum, n.7 : 37-55.

\section{AUCUSTINS, Georges}

1989 Comment se perpétuer? Devenir des lignées et destins dês patrimoines dans lês paysanneries européennes. Nanterre, Société d'ethnologie.

2000 “À quoi servent les terminologies de parenté?". L'Homme, vol. 154 : 573-598.

BÄHR, Gerhard

1935 Los nombres de parentesco en Vascuence. Bermeo, Gaubeka.

BARNES, John A.

1960 "Marriage and Residential Continuity". American

Anthropologist, vol. 62: 850-866.

BATESON, Gregory

[1972] 1998 Pasos hacia una ecología de la mente. Buenos Aires, Lohlé-Lumen.

[1979] 2011 Espíritu y naturaleza. Buenos Aires, Amorrortu.

CARO BAROJA, Julio

[1943] 1973 Los pueblos del Norte. San Sebastián, Txertoa.

[1944] 1974 De la vida rural vasca (Vera de Bidasoa):

Estudios Vascos IV. San Sebastián, Txertoa.

[1949] 1971 Los vascos. Madrid, Istmo.

[1956] 1976 Baile, familia, trabajo: estudios vascos VII. San Sebastián, Txertoa.

[1957] 1986 Vasconiana: estudios vascos III. San Sebastián, Txertoa.

1969 "Sobre la casa, su 'estructura' y sus 'funciones'". Cuadernos de Etnología y Etnografía de Navarra, vol. I (1): 35-66.

1982 La casa en Navarra. Tomos I, II, III y IV. Pamplona,

Caja de Ahorros de Navarra.

CARSTEN, Janet e HUCH-JONES, Stephen

1995 About the House. Lévi-Strauss and Beyond.

Cambridge, Cambridge University Press. 
CHACÓN, Francisco e BESTARD, Joan (orgs.)

2011 Familias: historia de la sociedad española (del final de la edad media a nuestros días). Madrid, Cátedra.

DOUCLASS, William A.

1969 Death in Murelaga: Funerary Ritual in a Spanish Basque Village. Seattle, University of Washington Press.

1975 Echalar and Murelaga. Opportunity and Rural Exodus in Two Spanish Basque Villages. Nova York, St. Martin's Press.

1988 "The Basque Stem Family Household: Myth or Reality?". Journal of Family History, vol. 13, n. 1: 75-89.

DUBY, Ceorges e LE GOFF, Jacques

1977 Famille et parenté dans l'Occident médiéval: Actes du colloque de Paris (6-8juin 1974). Roma, École française de Rome.

DUMONT, Louis

1975 Introducción a dos teorias de la Antropologia Social. Barcelona, Anagrama.

EFE, Bilbao

2013 "El euskera podría proceder del dogón hablado en Mali".

Diario de Navarra, Pamplona, 04 de abril de 2013.

ETNIKER, Euskalerria

2011 Atlas etnográfico de Vasconia: casa y familia en Vasconia. Bilbao, Labayru Ikastegia.

EZQUERRA, Alberto S.

1994 Baserria. Donostia, Guipuzkoako Foru Aldundia.

FAUVE-CHAMOUX, Antoinette e OCHIAI, Emiko (orgs.)

2009 The Stem Family in Eurasian Perspective: Revisiting House Societies, 17th-2oth Centuries. Berlim, Peter Lang.

FREEMAN, John Derek

1958 "The Family System of the Iban of Borneo". Cambridge Papers in Social Anthropology, n.1: 15-52.

1961 "On the Concept of Kindred". JRAl, vol. 91, n.2: 192-220.

1970 "The Iban of Western Borneo". In HARDING, T. G. e WALLACE, B. J. (orgs.). Cultures of the Pacific. Nova York, The Free Press, pp. 180-199. 


\section{GREENWOOD, Davydd}

1976 Unrewarding Wealth: The Commercialization and Collapse of Agriculture in a Spanish Basque Town. Cambridge, Cambridge University Press.

COODY, Jack (org.)

1983 The Development of the Family and Marriage in Europe.

Cambridge, Cambridge University Press.

2000 The European Family. Londres, Willey-Blackwell.

HAMEL, Elisabeth e VENNEMANN, Theo

2003 "El vascón fue la lengua originaria del continente".

Investigación y Ciencia, n.316: 62-71.

HERZFELD, Michael

[2005] 2008 Intimidade cultural: poética social no estado-nação. Lisboa, Edições 70.

IBARRA MURILLO, Orreaga

2002 "Erroibarko eta esteribarko oikonimoak (I)". Fontes Linguae Vasconum, n.91: 493-515.

JAUREGI, Oroitz

2005 Correspondencia de Gerhard Bähr com R. M. Azkue, H. Schuchardty].

Urquijo (1920-1944). San Sebastián, Diputación Foral de Gruipuzkoa.

KROEBER, Alfred L.

[1909] 1973 "Sistemas Classificatórios de Parentesco". In LARAIA,

R. (org.). Organização social. Rio de Janeiro, Zahar.

LE PLAY, Frederic

1895 L'Organisation de la famille selon le vrai modelé signale par l'histoire de toutes les races et de tous les temps. Tours, A. Mame et fils.

LEACH, Edmund R.

1951 "The Structural Implications of Matrilateral CrossCousin Marriage". JRAI, Vol. 81, pp. 23-55.

1962 "On Certain Unconsidered Aspects of Double Descent Systems". MAN, Vol. 62, pp. 130-134. 
ARTICo | Ion F. de las Heras | A casa do tio e a casa do sogro:

LÉVI-STRAUSS, Claude

[1949] 1982 As estruturas elementares de parentesco. Petrópolis, Vozes.

[1958] 2012 Antropologia estrutural. São Paulo, Cosac Naify.

[1979] 1981 A via das máscaras. Porto, Presença.

[1984] 1986 Minhas Palavras. São Paulo, Brasiliense.

1987 Anthropology and Myth: Lectures 1951-1982. Oxford, Blackwell.

LISÓN TOLOSANA, Carmelo e OZANAM, D.

1986 Los Pirineos: estudios de Antropologia Sociale História. Coloquio

Hispano-Francés. Madrid, Universidad Complutense.

LOWIE, Robert H.

1919 "The Matrilineal Complex". University of California Publications

in American Archaeology and Ethnology, vol. 16, n.2: 29-43.

1928 "A Note on Relationship Terminologies".

American Anthropologist, n.30: 263-267.

MACHADO, Igor José de Renó

2013 A antropologia de Schneider. Pequena introdução. São Carlos, EdUFSCar.

MALINOWSKI, Bronislaw

1930 "Kinship". Man, n.30: 19-29.

MARÍN PAREDES, José Antonio

1998 "Semejante Pariente Mayor": parentesco, solar, comunidad y linaje em la institución de un Pariente Mayor en Guipuzkoa: los señores del solar de Oñaz y Loyola (siglos XIV-XVI). San Sebastián, Diputación Foral de Guipuzkoa.

MICHELENA, Luis (Koldo)

1969 "Sobre algunos nombres vascos de parentesco".

Fontes Linguae Vasconum, n.2: 113-132.

1989 Apellidos Vascos. Donostia, Txertoa.

MORGAN, Lewis $\mathrm{H}$.

1871 Systems of Consanguinity and Affinity of the Human

Family. Washington, Smithsonian.

MORRIS, Michael Ashley

2012 Concise Dictionary of Social and Cultural

Anthropology. Oxford, Wiley-Blackwell. 
MURDOCK, George Peter

1949 Social Structure. Nova York, Macmillan.

1957 "World Ethnographic Sample". American Anthropologist, n.59, pp. 664-687.

NEEDHAM, Rodney

1956 “'Utrolateral' and 'Utrolocal'. Man, n. 169-171: 181.

OLIVERI KORTA, Oihane

2001 Mujer y herencia en el estamento hidalgo guipuzcoano durante el Antiguo

Régimen (Siglos XVI-XVIII). San Sebastián, Diputación Foral de Gipuzkoa.

2009 Mujer, casa y estamento en la Gipuzkoa del Siglo XVI. San

Sebastián, Diputación Foral de Gipuzkoa.

OTT, Sandra

1981 The Circle of Mountains: A Basque Shepherding

Community. Oxford, Clarendon Press.

PERISTIANY, John G.

1987 Dotey matrimonio en los países mediterráneos. Madrid, CIS.

PINA-CABRAL, João

1991 Os contextos da antropologia. Lisboa, Difel.

PORQUERES I GENÉ, Enric

2007 "Kinship Language and the Dynamics of Race: The Basque Case". In WADE, P. (org.). Race, Ethnicity and Nation: Perspectives from Kinship and Cenetics. Oxford, Berghahn Books.

RADCLIFFE-BROWN, Alfred R.

1924 "The Mother's Brother in South Africa". South

African Journal of Science, vol. 21: 541-555.

1969 [1941] "O estudo dos sistemas de parentesco". In LARAIA,

R. (org.). Organização social. Rio de Janeiro, Zahar.

RIDRUEJO, Carmelo

1983 "Julio Caro Baroja estudia la casa de Navarra en su obra más original e intensa". El País, Madrid, 13 de mayo de 1983. 
RIVERS, William H. R.

[1913]1991 "O sistema classificatório e formas de organização social". In OLIVEIRA, R. C. (org.). A antropologiade Rivers. Campinas, Unicamp.

\section{SCHMIDT, Carl}

1957 "Zur Problematik von Familie, Sippe und Geschlecht, Haus und Dynastie beim mittelalterlichen Adel: Vorfragen zum Thema "Adel und Herrschaft im Mittelalter"'. Zeitschrift für die Geschichte des Oberrheins, bd. 105: 1-62.

SCHNEIDER, David M.

[1965] 2011 "Some muddles in the models: or, how the system really works". HAU, vol. 1(1): 451-492.

1984 A Critique of the Study of Kinship. Ann Arbor, The University of Michigan Press.

SILVA, Marcio Ferreira da

2001 "1871: o ano que não terminou". Cadernos de campo, n.19: 323-336.

SORIA SESÉ, Lourdes

2006 "La hidalguía universal". Iura Vasconiae, n.3: 283-316.

TODD, Emmanuel

1990 L'Invention de L'Europe. Paris, Éditions du Seuil.

VINSON, Julien

1908 "Études sur le vocabulaire Básque". Revue de linguistique et de philologie comparée, tome 41: 81-96.

VIVEIROS DE CASTRO, Eduardo

2005 A inconstancia da alma selvagem. São Paulo, Cosac\&Naify.

ZULAIKA, Joseba

1990 Violencia vasca: metáfora y sacramento. Madrid, Nerea.

2000 Del cromañon al carnaval: los vascos como museo antropológico. Zarautz, Erein. 


\section{ABSTRACT}

I intend to show how the progressive attention given by the anthropology developed in the Basque Country to etxea, the concept that links home and family in Basque, throughout the 2oth century, was not the product of a properly native positive theory, but the result of a reaction to the mainstream debate of the anthropological theory, which was specially involved in the study of kinship terminology during several decades. I shall go through some relevant moments along this path, drawing a parallel with the theoretical strategies that Freeman, Lévi-Strauss and Schneider put forth to deal with problems concerning the inadequacy of theoretical concepts in certain forms of social organization. Thus, considering an epistemological perspective that takes systemically anthropological practice, I will try to indicate the possibilities of a dialogue between methodologies.

Recebido em 21 de setembro de 2016. Aceito em 30 de março de 2017.

\section{KEYWORDS}

Basque Country, Etxea, House, Kinship Terminology, Anthropological Methodology 